\title{
BMJ A cross-sectional study of the open appropriateness of colonoscopy requests in the Spanish region of Catalonia
}

\author{
Diana Puente, ${ }^{1,2}$ Francesc Xavier Cantero, ${ }^{3}$ Maria Llagostera, ${ }^{4}$ Pilar Piñeiro, ${ }^{5}$ \\ Raquel Nieto, ${ }^{5}$ Rosa Saladich, ${ }^{6}$ Juanjo Mascort, ${ }^{7,8}$ Mercè Marzo, ${ }^{9}$ \\ Jesús Almeda, ${ }^{2,9,10}$ Manel Segarra, ${ }^{11}$ the CANCER-REAP Research Group
}

To cite: Puente D, Cantero FX, Llagostera M, et al. A cross-sectional study of the appropriateness of colonoscopy requests in the Spanish region of Catalonia. BMJ Open 2012;2:e002207. doi:10.1136/bmjopen-2012002207

- Prepublication history for this paper are available online. To view these files please visit the journal online (http://dx.doi.org/10.1136/ bmjopen-2012-002207).

Received 11 October 2012 Revised 11 October 2012 Accepted 30 October 2012

This final article is available for use under the terms of the Creative Commons Attribution Non-Commercial 2.0 Licence; see http://bmjopen.bmj.com

For numbered affiliations see end of article.

\section{ABSTRACT}

Introduction: Colonoscopies are being requested with increasing frequency in the last few years, as they are used both as a diagnostic and therapeutic procedure in several gastrointestinal diseases. Our purpose is to describe the appropriateness of colonoscopy requests issued both from primary care centres and from hospitals, according to the EPAGE II guidelines (European Panel on the Appropriateness of Gastrointestinal Endoscopy).

Methods and analysis: Cross-sectional study. Colonoscopy requests issued since January 2011 and received at the endoscopy units of all six reference hospitals serving the primary care centres of the South Metropolitan and Central Catalonia districts will be collected (total $=1500$ requests). Variables to be collected include gender, date of birth, origin of the request and reference hospital, priority of the procedure, type of clinician requesting the procedure, date and indication of request, abdominal examination performed, anal inspection examination performed, date of last colonoscopy if applicable, diagnosis and date of diagnosis. Using the available information and the EPAGE II website, colonoscopy requests will be assigned as an appropriateness score. The association between the variables collected and the EPAGE II scores will be assessed using a Student's t test and a $\chi^{2}$ test. A multilevel logistic model will be generated on the factors associated with the appropriateness of the requests.

Ethics and dissemination: Colonoscopy is a costly procedure and not free from complications. In order to increase cost effectiveness, reduce waiting lists and optimise resources, it is necessary to use tools such as the EPAGE II guidelines, which establish criteria to assess the appropriateness of colonoscopies. The purpose of this study is to describe the current situation and to discuss whether current clinical practice is appropriate. The results of the study will be published in the next few years. In consideration of the ethical principles and methods of the research study, approval was granted for the project.

\section{ARTICLE SUMMARY}

\section{Article focus}

- Colonoscopy requests have increased in the last few years.

- The fact that colonoscopy has become the gold standard for the diagnosis of colon diseases, the increased demand for health from the population, and the resulting increase in the number of colonoscopies being requested by clinicians are the main reasons of this increase.

- We are proposing a study whose primary objective is to describe the current situation of colonoscopy requests in our setting, based on the EPAGE II guidelines.

- We expect to find a level of appropriateness of $60 \%$ or higher.

Key messages

- The results of the study will be useful to assess whether the application of the EPAGE II guidelines fits our reality and may be adapted to our daily clinical practice, as there is no agreement among the different guidelines or sometimes even between family physicians and specialists.

- Thus, due to the variability existing in our setting concerning the appropriateness of colonoscopy request, we consider that is necessary the implementation of guidelines as EPAGE II.

Strengths and limitations of this study

- Colonoscopy requests will be collected consecutively; it is ensured that they originate on different levels of care.

- As requests will be collected by different clinicians at different sites, it is necessary to standardise criteria, in order to avoid both selection bias and EPAGE II scoring bias.

- Thus, an external clinician will perform a second review of the EPAGE II punctuations in order to guarantee the comparability of sites.

- The inadequacy of the information on the requests or the defects in collecting the information can be important limitations.

- This would make it difficult to determine the EPAGE score and for this reason a priori criteria are established. 


\section{INTRODUCTION}

Colonoscopy requests have increased steadily in the last few years, resulting in a significant burden on public health. ${ }^{1}$ The main reasons for this include: the superiority of colonoscopy versus non-invasive procedures in detecting diseases; the fact that colonoscopy has become the gold standard for the diagnosis of colon diseases, specifically colorectal cancer (CRC) $;^{2}$ the increased demand for health from the population, and the resulting increase in the number of colonoscopies being requested by clinicians. However, colonoscopies have potentially serious complications and are considerably expensive procedures.

The importance of the appropriateness of colonoscopies has been a focus of debate for years, ${ }^{3-6}$ in an effort to manage available resources rationally. ${ }^{7}$ This has now become even more important in the context of the current economic situation. In this regard, Grassini et at point to a clear relationship between education of primary care physicians and the appropriateness of the colonoscopies requested by them, thereby reducing costs and waiting lists. Indeed, primary care physicians are an essential part of a multidisciplinary approach including early detection of lesions and population screening as fundamental components. ${ }^{10}$

With this aim of rationalising resources, several guidelines have been published, such as the guidelines by the American Society for Gastrointestinal Endoscopy (ASGE) or the European Panel on the Appropriateness of Gastrointestinal Endoscopy (EPAGE). The EPAGE II guidelines ${ }^{4}$ are the update to the 1998 EPAGE guidelines. ${ }^{11}$ The EPAGE II guidelines were developed by a panel of 14 experts (gastroenterologists, primary care physicians, internists and surgeons) from different European countries: the UK, Denmark, Switzerland, Germany, Spain, France, the Netherlands, Norway and Italy. The criteria for appropriateness of colonoscopies are defined based on the interrelation of characteristics such as gender and age, underlying disease, signs and symptoms and previous investigations. ${ }^{12-16}$ The appropriateness of the procedure is classified using a score between 1 (extremely inappropriate) and 9 (extremely appropriate).

Terraz et $a l^{17}$ concluded that the EPAGE guidelines are acceptable and easily managed but their widespread use may face organisational and cultural barriers, such as the enormous variability found in the requests for follow-up of polyps. In this case, the EPAGE II guidelines recommend that colonoscopy should be the first option in surveillance after polypectomy. ${ }^{12}$

Importantly, the more appropriate colonoscopies are, the higher their diagnostic yield, that is, the better these procedures are for detecting a lesion that is potentially important for the patient, ${ }^{4}{ }^{18}$ such as CRC. ${ }^{19}$ However, there are studies in the literature that consider the use of the EPAGE and ASGE guidelines inadequate for the detection of CRC. ${ }^{720}$
Considering all the above, we are now proposing a study whose primary objective is to describe the current situation in terms of appropriateness of colonoscopy requests in our setting, based on the EPAGE II guidelines. We expect to find a level of appropriateness of $60 \%$ or higher.

\section{METHODS AND ANALYSIS \\ Design}

This will be a descriptive, cross-sectional study.

\section{Setting}

Primary care clinics in the South-Metropolitan and Central Catalonia districts assigned to the following reference hospitals: Hospital Universitari de Bellvitge, Hospital de Viladecans, Hospital Alt Penedès, Hospital Sant Joan Despí Moisès Broggi, Hospital General de L'Hospitalet and Hospital General d'Igualada.

\section{Study sample}

Colonoscopy requests for patients $>14$ years of age will be collected from January 2011 until the target sample size is completed. Requests for in-patients and patients in screening programmes will be excluded.

\section{Sample size}

A sample of 1440 subjects as a minimum is required to determine an appropriateness level of at least $50 \%$ with an absolute precision of $4 \%$ and a $95 \%$ CI. It is expected that $20 \%$ of requests will be considered ineligible. In the endoscopy unit of each hospital, colonoscopy requests will be collected up to the target number of 1500 requests (calculations were performed using Epidat 3.1).

\section{Data collection}

All colonoscopy requests issued during the study period will be collected systematically until the target sample size is accrued. At the endoscopy units and gastroenterology departments of the participating hospitals, colonoscopy requests will be identified and collected; in addition, the patient's hospital record and the results and diagnostic data obtained from the colonoscopies will be documented. A collection period of 6 months is expected to be needed.

This information will be collected by clinician auditors (physicians and nurses) using an optical data collection sheet (Teleform V.4.0 for Windows).

\section{Variables}

- Social and demographic patient characteristics: gender, age, allocated primary care facility and reference hospital.

- Clinician requesting the procedure: family physician, gastroenterologist, internist, surgeon or other.

- Colonoscopy requests:

- Date of request

- Priority of request: routine, priority and emergency 
- Indication: opportunistic screening, diagnostic suspicion based on signs and symptoms of colorectal diseases (anaemia, rectal bleeding, constitutional syndrome, depositional changes, abdominal pain and others), or follow-up of: polyps (type), cancer, ulcerative colitis, Crohn's disease, diverticular disease or other

- Abdominal examination: performed, not recorded

- Anal inspection: normal, abnormal and not recorded

- Digital rectal examination: normal, abnormal and not recorded

- Date of last colonoscopy if applicable; colonoscopy requests for disease follow-up will be excluded if the date of the previous colonoscopy cannot be determined.

- Results and diagnosis:

- Date of the procedure and hospital where performed

- Anal inspection: normal, abnormal and not recorded

- Digital rectal examination: normal, abnormal and not recorded

- Results: normal, polyps (type), cancer, ulcerative colitis, Crohn's disease, diverticular disease, haemorrhoids or other.

- Level of appropriateness according to EPAGE II: 1-9 (where 1 is extremely inappropriate and 9 is extremely appropriate). The EPAGE score will be determined based on the information available on the data collection sheet. If any information is missing, data will be retrieved from the hospital records in an effort to score the colonoscopy. Because the EPAGE score varies based on the indication initiating the calculation algorithm, a number of a priori criteria have been established: for requests issued for more than one indication (oportunistic screening, symptom and follow-up), the symptom will be given priority first, then follow-up and lastly screening; haematochezia will be considered to be bright red blood unless otherwise specified; in case of no recorded family history or other risk factors, it will be assumed that there are none; in the case of several symptoms, the symptom of poorest prognosis will be considered when only one symptom is required. If there is no information on polyp type or if there is more than one polyp, the polyp of poorest prognosis will be considered; if the performance of the colonoscopy is incomplete or preparation is poor, 'other' will be entered as the diagnostic category. As colonoscopies will be collected by different clinicians an external reviewer will perform a second review of the scores obtained from the guidelines, in order to standardise criteria.

\section{Analysis}

A descriptive analysis will be carried out on the characteristics of the population for which colonoscopies are requested.
According to the EPAGE II scores, three groups will be established based on whether the request is appropriate (7-9), uncertain (4-6) or inappropriate (1-3). The percentage of requests of each level will be determined in each group. Following the same method, the percentage of appropriateness of the colonoscopy requests for polyp follow-up will be determined separately, as this is considered to be a specific group. Subsequently, a descriptive analysis will be performed after stratification for level of care (hospitals vs primary care clinics), specialty of the requesting clinician and indication for the request. Also, an analysis for establishing the association between EPAGE (three groups) and the results of colonoscopy will be performed.

In addition, bivariate and multivariate analyses will be performed on the factors predisposing to appropriate versus inappropriate requests (cut-off point of 4 on the EPAGE II scoring system). Patient factors and clinician and hospital factors will be considered, based on statistical significance and clinical relevance.

Finally a secondary analysis will be conducted in order to establish the concordance between the score from before and after the peer reviewed.

\section{DISCUSSION, ETHICS AND DISSEMINATION}

Colonoscopy is an expensive procedure and is not free from complications. In order to increase costeffectiveness, reduce waiting lists and optimise resources, it is important to ensure the right appropriateness of these procedures. Improving appropriateness results in improved diagnostic yield and a reduction in the number of unnecessary procedures, thereby lowering the risk of complications, especially in healthy subjects. For these reasons, it is necessary to use tools such as the EPAGE II guidelines, which establish criteria for evaluating the indication of colonoscopies. ${ }^{21} 22$

A number of studies have assessed the appropriateness of colonoscopies according to the EPAGE II guidelines ${ }^{19}{ }^{21}$ or the ASGE guidelines, ${ }^{23}$ showing that $16-30 \%$ of colonoscopy requests are inappropriate. This percentage is even higher for colonoscopies requested for surveillance of adenomas after polypectomy $(70.6 \%$ of inappropriate requests). ${ }^{21}$

Nevertheless, it should be noted that, even if the EPAGE II criteria are helpful for decision-making, the individual assessment of the patient must be considered as well. ${ }^{24}$

This study will collect all colonoscopy requests issued consecutively from January 2011, with their relevant diagnostic data. Patients may be referred from both primary care and specialist clinics. Because requests will be collected consecutively, it is ensured that they originate on different levels of care. Patients seen in private clinics will be excluded from our study, although patients who are seen at private centres are a minority in this setting.

Because requests will be collected by different clinicians at different sites, it is necessary to standardise 
criteria, in order to avoid both selection bias and EPAGE II scoring bias. Once the target number of requests has been collected, an external clinician will perform a second review of the EPAGE II scores and standardise the criteria with the participating clinicians to guarantee the comparability of sites. Thus, we do not expect there to be great variability in the EPAGE II scores between the participating sites, as the criteria to prioritise situations and patient symptoms will be standardised throughout the study group by the external clinician.

Another potential limitation for the study is the inadequacy of the information on the requests or the defects in collecting the information. This would make it difficult to determine the EPAGE score and for this reason a priori criteria have been established.

This will be a cross-sectional study. Therefore, the observations will be a reflection of the current situation, which will enable us to discuss whether current clinical practice is appropriate or whether, on the contrary, colonoscopies are being requested inappropriately. In addition, the results of the study will be useful to assess whether the application of the EPAGE II guidelines fits our reality and may be adapted to our daily clinical practice, as there is no agreement among the different guidelines or sometimes even between family physicians and specialists. Also, the results will be able to show if there is a correlation between EPAGE II criteria and endoscopic diagnosis of CRC or other pathologies. ${ }^{13} 19$

Another aspect that should be considered is the need to provide physicians with education on the available guidelines (EPAGE, ASGE, among others) as these guidelines have been shown to increase the quality of care. In addition, they are well-accepted, user-friendly tools for clinicians.

The results of the study need to be published in the next 2 years because our aim is to give rules to clinicians in order to improve their current medical practice.

At the meeting held on 22 December 2010, the Clinical Research Ethics Committee of IDIAP Jordi Gol reviewed this research project (P10/83), entitled 'A Study of the Appropriateness of Colonoscopy Requests: From Primary Care to the Hospital'. In consideration of the ethical principles and methods of the research study, approval was granted for the project.

\footnotetext{
Author affiliations

${ }^{1}$ Institut Universitari d'Investigació en Atenció Primària Jordi Gol (IDIAP Jordi Gol), Barcelona, Spain

${ }^{2}$ Universitat Autònoma de Barcelona, Bellaterra (Cerdanyola del Vallès), Spain

${ }^{3}$ EAP Igualada Urbà, Institut Català de la Salut, Igualada, Spain

${ }^{4}$ Gerència Territorial Metropolitana Sud, Institut Català de la Salut, L'Hospitalet del Llobregat, Spain

${ }^{5}$ Servei d'Atenció Primària (SAP) Penedès-Garraf-Llobregat Nord, ABS

Penedès Rural, Institut Català de la Salut, Alt Penedès, Spain

${ }^{6}$ EAP Sant Boi de Llobregat-4 (Vinyets), Institut Català de la Salut, Sant Boi de Llobregat, Spain

${ }^{7}$ EAP L'Hospitalet de Llobregat-8 (Florida Sud), Institut Català de la Salut, L'Hospitalet de Llobregat, Spain

${ }^{8}$ Campus Bellvitge, Universitat de Barcelona, L'Hospitalet del Llobregat, Spain

${ }^{9}$ Unitat de Suport a la Recerca Costa de Ponent, Institut Universitari
}

d'Investigació en Atenció Primària Jordi Gol (IDIAP Jordi Gol), Cornellà, Spain

${ }^{10}$ CIBER Epidemiología y Salud Pública (CIBERESP), Barcelona, Spain

${ }^{11}$ EAP Hospitalet de Llobregat-1 (Centre), Institut Català de la Salut,

L'Hospitalet de Llobregat, Spain

Acknowledgements We would like to thank all clinicians for their participation in data collection, which enabled the conduct of this study. We would also like to thank the Institut Universitari d'Investigació en Atenció Primària Jordi Gol for its support in the translation of papers.

Contributors All authors make up the core team of researchers in the project: 'A Study of the Appropriateness of Colonoscopy Requests: From Primary Care to the Hospital'. FXC, MLL, PP, RN, RS, JM and MS are the field work coordinators. DP is responsible for cleanup and maintenance of the database. DP and FXC participated in drafting of the paper. MM will perform the second review of the EPAGE scores and standardise them with the rest of the group. JA will participate as a consultant throughout the process, both for field work and for drafting of the protocol, analysis of results and securing of funds. All authors have read and approved the final manuscript.

Funding This study was granted with the first prize at the sixth edition of the 'Premis Recerca en Atenció Primària Regió Sanitària de Barcelona 2010' awards (awards to research in primary care in the healthcare area of Barcelona). This made it possible to obtain the funds needed for the study.

\section{Competing interests None.}

Ethics approval Clinical Research Ethics Committee of IDIAP Jordi Gol (P10/83)

Provenance and peer review Not commissioned; externally peer reviewed.

Data sharing statement The information of patient characteristics, those used in our study and those not used are available in the electronical clinical records reported system of Catalan Institute of Health in Catalonia (Spain).

\section{REFERENCES}

1. Arguello L, Pertejo V, Ponce M, et al. The appropriateness of colonoscopies at a teaching hospital: magnitude, associated factors, and comparison of EPAGE and EPAGE-II criteria. Gastrointest Endosc 2012;75:138-45.

2. Burke CA, Elder K, Lopez R. Screening for colorectal cancer with flexible sigmoidoscopy: is a 5-yr interval appropriate? A comparison of the detection of neoplasia 3 yr versus $5 \mathrm{yr}$ after a normal examination. Am J Gastroenterol 2006;101:1329-32.

3. Adler A, Roll S, Marowski B, et al. Berlin Private-Practice Gastroenterology Working Group: appropriateness of colonoscopy in the era of colorectal cancer screening: a prospective, multicenter study in a private-practice setting (Berlin Colonoscopy Project 1 , BECOP 1). Dis Colon Rectum 2007;50:1628-38.

4. Balaguer F, Llach J, Castells A, et al. The European panel on the appropriateness of gastrointestinal endoscopy guidelines colonoscopy in an open-access endoscopy unit: a prospective study. Aliment Pharmacol Ther 2005;21:609-13.

5. Fernandez-Esparrach G, Gimeno-Garcia AZ, Llach J, et al. Recomendaciones de utilización de la endoscopia: análisis de la probabilidad de encontrar lesiones significativas en los pacientes procedentes de la atención extrahospitalaria. Med Clin (Barc) 2007;129:205-8.

6. Harris JK, Froehlich F, Gonvers JJ, et al. The appropriateness of colonoscopy: a multi-center, international, observational study. Int $J$ Qual Health Care 2007;19:150-7.

7. Hassan C, Di Giulio E, Pickhardt PJ, et al. Cost effectiveness of colonoscopy, based on the appropriateness of an indication. Clin Gastroenterol Hepatol 2008;6:1231-6.

8. Suriani R, Rizzetto M, Mazzucco D, et al. Appropriateness of colonoscopy in a digestive endoscopy unit: a prospective study using ASGE guidelines. J Eval Clin Pract 2009;15:41-5.

9. Grassini M, Verna C, Battaglia E, et al. Education improves colonoscopy appropriateness. Gastrointest Endosc 2008;67:88-93.

10. Aranda Hernández J, Aguilar-Shea AL, Marín Gabriel J. Podemos estar tranquilos ante una colonoscopia sin lesiones? Cáncer colorrectal de intervalo. Aten Primaria 2011;43:333-5.

11. Vader JP, Wietlisbach V, Harris JK, et al. Gastroenterologists overestimate the appropriateness of colonoscopies they perform: an international observational study. Endoscopy 2005;37:840-6. 
12. Arditi C, Gonvers JJ, Burnand B, et al. EPAGE II Study Group: appropriateness of colonoscopy in Europe (EPAGE II). Surveillance after polypectomy and after resection of colorectal cancer. Endoscopy 2009;41:209-17.

13. Arditi C, Peytremann-Bridevaux I, Burnand B, et al. EPAGE II Study Group: appropriateness of colonoscopy in Europe (EPAGE II). Screening for colorectal cancer. Endoscopy 2009;41:200-8.

14. Peytremann-Bridevaux I, Arditi C, Froehlich F, et al. EPAGE II Study Group: appropriateness of colonoscopy in Europe (EPAGE II). Iron-deficiency anemia and hematochezia. Endoscopy 2009;41:227-33.

15. Schusselé Filliettaz S, Gonvers JJ, Peytremann-Bridevaux I, et al. EPAGE II Study Group: appropriateness of colonoscopy in Europe (EPAGE II). Functional bowel disorders: pain, constipation and bloating. Endoscopy 2009;41:234-9.

16. Schusselé Filliettaz $S$, Juillerat $P$, Burnand B, et al. EPAGE II Study Group: appropriateness of colonoscopy in Europe (EPAGE II). Chronic diarrhea and known inflammatory bowel disease. Endoscopy 2009;41:218-26.

17. Terraz O, Wietlisbach V, Jeannot JG, et al. The EPAGE internet guideline as a decision support tool for determining the appropriateness of colonoscopy. Digestion 2005;71:72-7.

18. Siddique I, Mohan K, Hasan F, et al. Appropriateness of indication and diagnostic yield of colonoscopy: first report based on the 2000 guidelines of the American Society for Gastrointestinal Endoscopy. World J Gastroenterol 2005;11:7007-13.

19. Carrion S, Marin I, Lorenzo-Zuniga V, et al. Adecuación de las indicaciones de colonoscopia según los nuevos criterios de EPAGE II. Gastroenterol Hepatol 2010;33:484-9.

20. Hassan C, Di GE, Marmo R, et al. Appropriateness of the indication for colonoscopy: systematic review and meta-analysis. $J$ Gastrointestin Liver Dis 2011;20:279-86.

21. Adán Merino L, Mora Sanz P, Turrión J, et al. Adecuación en las indicaciones de colonoscopias en un hospital de tercer nivel: estudio prospectivo. Revista de la ACAD 2010;XXVI:37-41.

22. Gimeno Garcia AZ, Gonzalez Y, Quintero E, et al. Clinical validation of the European Panel on the Appropriateness of Gastrointestinal Endoscopy (EPAGE) II criteria in an open-access unit: a prospective study. Endoscopy 2012;44: 32-7.

23. Petruzziello L, Hassan C, Alvaro D, et al. Appropriateness of the indication for colonoscopy: is the endoscopist the 'Gold Standard'? J Clin Gastroenterol 2012;46:590-4.

24. Juillerat P, Peytremann-Bridevaux I, Vader JP, et al. Appropriateness of colonoscopy in Europe (EPAGE II). Presentation of methodology, general results, and analysis of complications. Endoscopy 2009;41:240-6. 